\title{
Utilização de xilanase em dietas compostas por milho e farelo de soja de poedeiras comerciais em postura ${ }^{1}$
}

\author{
Maurício Tárcio dos Santos Viana ${ }^{2}$, Luiz Fernando Teixeira Albino ${ }^{3}$, Horacio Santiago \\ Rostagno $^{3}$, Eliane Aparecida da Silva ${ }^{4}$, Rodolfo Alves Vieira ${ }^{5}$, Valdir Ribeiro Junior ${ }^{5}$
}

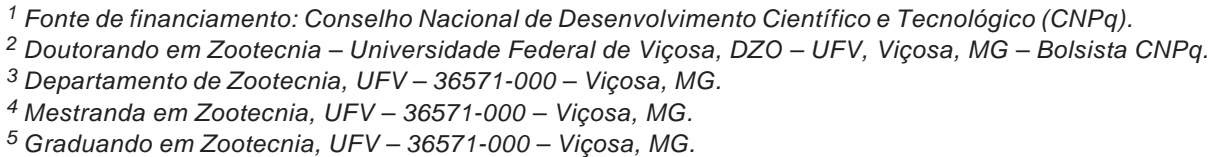

1 Fonte de financiamento: Conselho Nacional de Desenvolvimento Científico e Tecnológico (CNPq).

2 Doutorando em Zootecnia - Universidade Federal de Viçosa, DZO - UFV, Viçosa, MG - Bolsista CNPq.

3 Departamento de Zootecnia, UFV - 36571-000 - Viçosa, MG.

${ }^{4}$ Mestranda em Zootecnia, UFV - 36571-000 - Viçosa, MG.

5 Graduando em Zootecnia, UFV - 36571-000 - Viçosa, MG.

RESUMO - Objetivou-se avaliar o efeito da adição da enzima xilanase (Econase XT25) sobre o metabolismo de nutrientes e o desempenho de poedeiras no período de 24 a 48 semanas de idade. Foram utilizadas 288 poedeiras, distribuídas em delineamento experimental inteiramente casualizado em arranjo fatorial $2 \times 2$, com dois níveis de energia metabolizável (2.900 e $2.755 \mathrm{kcal} / \mathrm{kg}$ ) combinados ou não com a adição de xilanase (37,5 g/t de ração), totalizando quatro tratamentos (controle positivo; controle negativo; controle positivo + xilanase; e controle negativo + xilanase), avaliados com 12 repetições de 6 aves por unidade experimental. As dietas controle positivo e controle positivo + xilanase foram formuladas seguindo as recomendações das Tabelas Brasileiras (100\% de energia metabolizável), enquanto as dietas controle negativo e controle negativo + xilanase foram calculadas reduzindo $5 \%$ da energia metabolizável. A adição da enzima xilanase à dieta controle negativo proporcionou produção de ovos e massa de ovos semelhante às observadas no grupo controle positivo. A redução de 5\% de energia metabolizável ocasionou diminuição na produção de ovos, na massa de ovos, piora da conversão alimentar e aumento do consumo de ração. A composição dos ovos não foram influenciada pelas dietas. Os valores médios de energia metabolizável aparente corrigida são maiores em dietas com maior nível de energia metabolizável. A adição de xilanase melhorou a utilização da energia e a produção de ovos em dietas para galinhas poedeiras.

Palavras-chave: desempenho, energia metabolizável, enzimas, metabolismo, poedeiras

\section{Use of xylanase in diets composed of corn and soybean meal for comercial laying hens}

\begin{abstract}
The objective of this study was to evaluate the effect of the addition of xylanase enzyme (Econase XT25) on the metabolism of nutrients and the performance of laying hens from 24 to 48 weeks of age. It was used 288 laying hens, distributed in a completely randomized design in a $2 \times 2$ factorial arrangement, with two levels of metabolizable energy (2,900 and $2,755 \mathrm{kcal} / \mathrm{kg}$ ) combined or not with addition of xylanase enzyme (37.5 g/t of ration), totaling four treatments (positive control, negative control, positive control + xylanase; and negative control + xylanase), evaluated with 12 replicates of 6 birds per experimental unit. Positive control and positive control + xylanase diets were formulated following the recommendations by Tabelas Brasileiras (100\% metabolizable energy) while negative control and negative control + xilanase diets were calculated by reducing $5 \%$ of metabolizable energy. The addition of xylanase enzyme to the negative control diet provided egg production and egg mass similar to the ones observed in the positive control group. Reduction of $5 \%$ of metabolizable energy resulted in a decrease in egg production, in egg mass, worsening in feed conversion and increase in feed intake. Composition of the eggs was not affected by the diets. The average values of corrected apparent metabolizable energy are higher in diets with higher level of metabolizable energy. The addition of enzyme xylanase improved the use of energy and egg production in diets for laying hens.
\end{abstract}

Key Words: enzymes, laying hens, metabolism, metabolizable energy, performance

\section{Introdução}

Apesar da constante busca por alimentos alternativos, as dietas para aves ainda são formuladas basicamente com milho e farelo de soja. No entanto, o farelo de soja apresenta em sua composição polissacarídeos nãoamiláceos, componentes não-digeríveis pelas aves ou de digestão incompleta (Zanella, 1999). A presença desses 
polissacarídeos aumenta a viscosidade do alimento no trato gastrintestinal, reduzindo a digestão e absorção de aminoácidos, carboidratos, minerais e outros nutrientes, diminuindo a produtividade das aves (Bedford et al., 1991).

O farelo de soja apresenta $20 \%$ de polissacarídeos não-amiláceos com digestibilidade praticamente nula (Cantor, 1995). Além disso, os inibidores de tripsina e as lectinas são os fatores antinutricionais do farelo de soja mais comumente destacados na literatura. Como as aves não secretam enzimas endógenas necessárias para a ruptura dos $\beta$-glucanos, arabinoxilanos e outras fibras solúveis ou insolúveis presentes nos cereais, o aumento na viscosidade inevitavelmente prejudica a digestão e absorção dos nutrientes no trato digestivo das aves (Classen \& Campbell, 1985).

No intuito de melhorar o valor nutritivo de dietas compostas de milho e farelo de soja, sugeriu-se no início da década de 90 o uso de complexos enzimáticos. Assim, o uso de enzimas capazes de neutralizar os fatores antinutricionais do milho e do farelo de soja pode melhorar a qualidade nutricional da dieta e promover desempenho animal mais uniforme (Wyatt \& Bedford, 1998). Segundo Silva et al. (2000), as enzimas exógenas aumentam a digestibilidade e a eficiência dos alimentos, reduzindo a ação de inibidores de crescimento e auxiliando as enzimas endógenas nos processos digestivos.

O principal objetivo da utilização de enzimas em dietas à base de milho e farelo de soja é possibilitar aproveitamento máximo dos nutrientes da dieta e, com isso, melhorar os resultados produtivos das aves (Fuente \& Soto-Salanova, 1997). Assim, realizou-se este trabalho com o objetivo de avaliar a influência da adição da enzima xilanase (160.000 $\mathrm{BXU} / \mathrm{g}$ ) em dietas à base de milho e farelo de soja sobre o desempenho e o metabolismo de poedeiras comerciais em postura.

\section{Material e Métodos}

Dois ensaios foram conduzidos no Setor de Avicultura do Departamento de Zootecnia da Universidade Federal de Viçosa no período de 26 de abril a 11 de outubro de 2007. Inicialmente as aves foram selecionadas de acordo com o peso corporal para uniformização do lote e, por um período de 28 dias, a produção foi controlada individualmente para posterior redistribuição para equalização da produção.

No ensaio 1, foram utilizadas 288 galinhas poedeiras da linhagem Bovans Goldline, de 24 a 48 semanas de idade, durante 168 dias. As aves foram alojadas em galpão de alvenaria com cobertura de telhas de barro em duas águas, telado, com pé-direito de 2,0 m e composto internamente por gaiolas de arame galvanizado com quatro compartimentos de $25 \times 45 \times 40 \mathrm{~cm}$ (largura, profundidade e altura), distribuídas lateralmente em dois andares (o de baixo posicionado a $0,80 \mathrm{~m}$ do piso). O comedouro e o bebedouro utilizados foram do tipo calha galvanizada percorrendo toda a extensão frontal das gaiolas.

Durante todo o período experimental, a temperatura no interior do galpão foi monitorada diariamente, duas vezes ao dia (às 8 e 16 h), utilizando-se termômetros de máxima e mínima. As aves receberam ração e água à vontade e 17 horas de luz/dia durante todo o período experimental, respeitando as recomendações de manejo do manual da linhagem. Os ovos foram colhidos duas vezes ao dia (às 8 e 16 h), com anotação, em fichas apropriadas, da frequência de postura e da mortalidade das aves.

As aves foram distribuídas em delineamento inteiramente casualizado em arranjo fatorial $2 \times 2$, composto de dois níveis de energia metabolizável (2.900 e $2.755 \mathrm{kcal} / \mathrm{kg}$ em combinação, ou não, com a enzima xilanase no nível de 37,5 g/t de ração), resultando em quatro tratamentos, avaliados com 12 repetições de 6 aves por unidade experimental.

Seguindo as recomendações das Tabelas Brasileiras (Rostagno et al. 2005), as dietas experimentais consistiram em: controle positivo (energia metabolizável 100\%), controle negativo (energia metabolizável 95\%); controle positivo + xilanase; e controle negativo + xilanase (Tabela 1).

As características de desempenho avaliadas foram: consumo de ração (g/ave/dia), determinado pela diferença entre o peso da ração fornecida e o peso da sobra de ração nos comedouros e recipientes em cada parcela ao término de cada período de 28 dias. Ao final do experimento, foi calculada a média do consumo nos seis períodos (168 dias); produção de ovos (\%/ave/dia), calculada dividindo-se o total de ovos produzidos pelo número de aves de cada parcela, e pelo número de dias vezes 100; peso dos ovos, onde todos os ovos íntegros nos cinco últimos dias de cada mês dentro do período experimental (28 dias) foram pesados para o cálculo do peso médio dos ovos; massa de ovos (g/ave/dia), como o produto da percentagem de ovos/ave/dia e do peso médio dos ovos em cada parcela; conversão alimentar por massa de ovos, calculada pela relação entre gramas de ração ingerida pelas aves e massa de ovo produzida em gramas; conversão alimentar por dúzia de ovos, calculada pela relação entre a quantidade de ração consumida $(\mathrm{kg})$ por dúzia de ovo produzida. 
Tabela 1 - Composição das dietas, na matéria natural

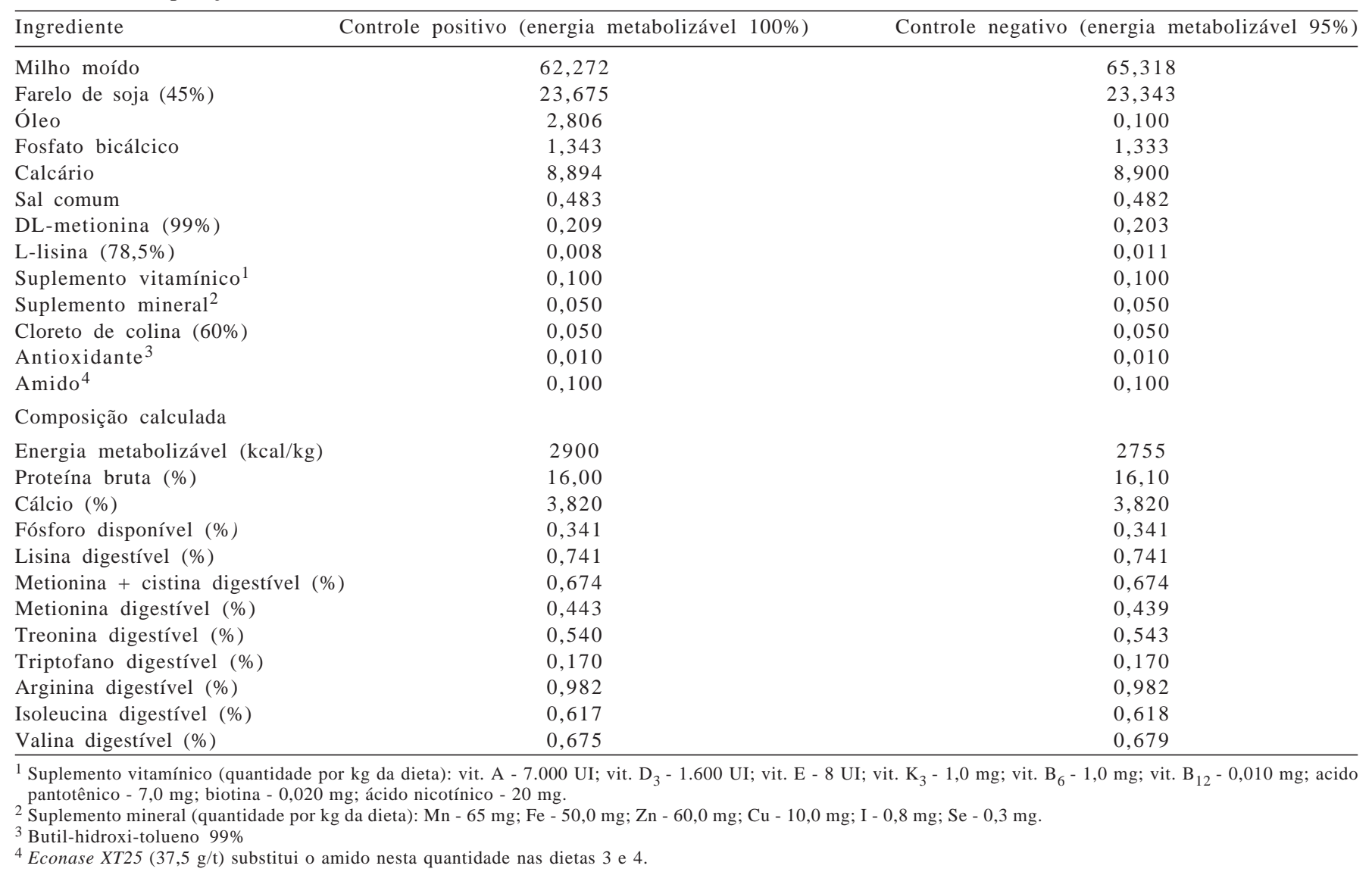

Para obtenção dos componentes do ovo, foram avaliados os pesos de gema, albúmen e casca utilizando-se seis ovos de cada repetição, coletados aleatória e diariamente do total de ovos coletados nos três últimos dias de cada período. Os ovos de cada repetição e de cada dia foram pesados individualmente em balança com precisão de 0,001 g e, depois de pesados, foram identificados e quebrados. A gema de cada ovo foi pesada e a respectiva casca foi lavada e seca ao ar para posterior obtenção do peso da casca sem a membrana interna. O peso do albúmen foi calculado como a diferença entre o peso do ovo e os pesos da gema e da casca.

No ensaio de metabolismo (ensaio 2), utilizaram-se, simultaneamente, as 288 poedeiras com 34 semanas de idade do ensaio 1, portanto, manteve-se o mesmo delineamento adotado no experimento de desempenho.

As rações fornecidas foram pesadas no início e no final do período total de coleta com a finalidade de se obter o consumo médio de ração e de energia bruta em cada repetição.

Sob as gaiolas foram colocas bandejas metálicas, revestidas com plásticos, permitindo a coleta das excretas, que foi feita diariamente, em intervalos de 8 horas, durante cinco dias. As excretas recolhidas em cada unidade experimental, após a eliminação de penas, resíduos de ração e outras fontes de contaminação, foram transferidas para sacos plásticos devidamente identificados, pesados e armazenados em freezer $\mathrm{a}-12^{\circ} \mathrm{C}$. Posteriormente, foram descongeladas, reunidas por repetição e homogeneizadas, retirando-se uma alíquota de $400 \mathrm{~g}$, que foi mantida em estufa de ventilação forçada por 72 horas a $55^{\circ} \mathrm{C}$, para secagem. Posteriormente, essas amostras foram pesadas, moídas e acondicionadas para as análises.

Foram anotadas as quantidades de rações consumidas e de excretas produzidas. As análises laboratoriais da matéria seca, do nitrogênio e do fósforo, das rações e das excretas seguiram a metodologia descrita por Silva (1990).

Todas as análises foram realizadas em duplicatas no Laboratório de Nutrição Animal do Departamento de Zootecnia da UFV. Os valores de energia bruta (EB) foram determinados por meio de bomba calorimétrica adiabática Parr. Após a obtenção dos resultados das análises laboratoriais das dietas e das excretas, foram calculados os coeficientes de metabolizabilidade aparente da matéria seca 
(CMAMS), da energia metabolizável corrigida (EMAn) e do seu respectivo coeficiente de metabolizabilidade (CMEMn); além do balanço de nitrogênio (BN). O coeficiente de metabolizabilidade (porcentagem de energia bruta metabolizada na forma de EMA e de EMAn) foi calculado utilizando-se os valores de energia metabolizável divididos pela energia bruta referente a cada tratamento. Determinaram-se também os valores médios de ingestão, de excreção e de retenção aparente de fósforo e de cálcio.

As análises estatísticas de ambos os experimentos foram feitas por análise de variância e, na ocorrência de efeito significativo, a comparação de médias entre tratamentos foi realizada pelo teste $\mathrm{F}$, a $5 \%$ de probabilidade, utilizando o software SAEG (2000) - Sistema de Análise Estatística e Genética, desenvolvido pela Universidade Federal de Viçosa - UFV.

\section{Resultados e Discussão}

A produção de ovos e a massa de ovos foram menores $(\mathrm{P}<0,05)$ e a conversão alimentar por massa de ovos, pior $(\mathrm{P}<0,05)$ no grupo alimentados com as dietas sem a adição de xilanase. No caso da ração com o menor nível de energia metabolizável (controle negativo + xilanase), a adição da xilanase melhorou $(\mathrm{P}<0,05)$ a produção de ovos e a massa de ovos em média 2,8\% em comparação à dieta controle de mesmo nível de energia metabolizável (controle negativo). No entanto, a taxa de postura e a massa de ovos das aves alimentadas com a ração controle negativo + xilanase não diferiram $(\mathrm{P}>0,05)$ do observado para as aves do grupo alimentado com a ração de maior nível de energia metabolizável (2.900 kcal/kg) sem suplementação de enzima (Tabela 2).

Não foram observados efeitos $(\mathrm{P}>0,05)$ da suplementação de xilanase sobre consumo de ração e conversão alimentar (g/g e kg/dúzia). Esses resultados diferem dos apresentados por Ny et al. (1998) e Mathlouthi et al. (2003), que detectaram melhora significativa na conversão alimentar de poedeiras alimentadas com rações suplementadas com enzimas. Entretanto, a redução do nível de energia das dietas aumentou o consumo de ração e piorou a conversão alimentar das aves, provavelmente porque, com a redução do nível de energia nas dietas, as aves passaram a se alimentar mais para manter o nível diário de ingestão de energia.

Da mesma forma, não houve efeito das dietas sobre o peso do ovo $(\mathrm{P}>0,05)$, resultado que está de acordo com relatos de Leeson (1996) de que o nível de energia em condições normais não influencia o tamanho do ovo. Ny et al. (1998) também verificaram que a redução de 3\% no valor energético da dieta não influencia o peso dos ovos.

Pack \& Bedford (1997) e Strada et al. (2005) observaram que a redução da densidade energética e aminoacídica em dietas à base de milho e farelo de soja e contendo enzimas não comprometeu o desempenho de frangos de corte e pode ser uma alternativa para redução dos custos de produção. De modo geral, a composição dos ovos avaliados não foi afetada $(\mathrm{P}>0,05)$ pelas dietas experimentais. Entretanto, entre as aves que receberam as dietas com o maior nível de energia metabolizável, verificou-se maior peso de gema (Tabela 3).

De acordo com Lecznieski (2006), em dietas com níveis adequados ou ligeiramente deficientes, a adição

Tabela 2 - Características produtivas de galinhas poedeiras alimentadas com rações suplementadas com xilanase

\begin{tabular}{|c|c|c|c|c|c|c|}
\hline \multirow[b]{2}{*}{ Xilanase } & \multicolumn{3}{|c|}{ Energia metabolizável (kcal/kg de ração) } & \multicolumn{2}{|c|}{ Energia metabolizável (kcal/kg de ração) } & \multirow[b]{2}{*}{ Média } \\
\hline & 2.900 & 2.755 & Média & 2.900 & 2.755 & \\
\hline & \multicolumn{3}{|c|}{ Consumo de ração (g/ave/dia) } & \multicolumn{2}{|c|}{ Peso dos ovos (g) } & \\
\hline Sem xilanase & 115,4 & 117,0 & 116,19 & 61,22 & 60,47 & 60,85 \\
\hline Com xilanase & 116,1 & 118,7 & 117,40 & 60,67 & 60,43 & 60,55 \\
\hline Média & $115,76 \mathrm{~A}$ & $117,84 \mathrm{~B}$ & & 60,95 & 60,45 & \\
\hline \multirow[t]{2}{*}{ Coeficiente de variação (\%) } & \multicolumn{2}{|c|}{2,02} & \multicolumn{3}{|c|}{1,87} & \\
\hline & \multicolumn{2}{|c|}{ Produção de ovos (\%) } & \multicolumn{4}{|c|}{ Massa de ovos (g/ave/dia) } \\
\hline Sem xilanase & $94,32 \mathrm{Aa}$ & $92,06 \mathrm{Bb}$ & $93,19 b$ & $57,77 \mathrm{Aa}$ & $55,75 \mathrm{Bb}$ & 56,76 \\
\hline Com xilanase & $94,01 \mathrm{Aa}$ & $94,70 \mathrm{Aa}$ & $94,35 a$ & 56,99 Аа & $57,33 \mathrm{Aa}$ & 57,16 \\
\hline Média & 94,16 & 93,38 & & $57,38 \mathrm{~A}$ & $56,54 \mathrm{~B}$ & \\
\hline \multirow[t]{2}{*}{ Coeficiente de variação (\%) } & \multicolumn{2}{|c|}{1,97} & \multicolumn{3}{|c|}{2,20} & \\
\hline & \multicolumn{2}{|c|}{$\begin{array}{c}\text { Conversão alimentar por } \\
\text { massa de ovos }(\mathrm{g} / \mathrm{g})\end{array}$} & \multicolumn{4}{|c|}{$\begin{array}{l}\text { Conversão alimentar por } \\
\text { dúzia de ovos (kg/dúzia) }\end{array}$} \\
\hline Sem xilanase & $1,998 \mathrm{Aa}$ & $2,093 \mathrm{Bb}$ & 2,045 & 1,467 & 1,519 & 1,493 \\
\hline Com xilanase & $2,038 \mathrm{Bb}$ & $2,070 \mathrm{Bb}$ & 2,054 & 1,484 & 1,509 & 1,496 \\
\hline Média & $2,018 \mathrm{~A}$ & $2,081 \mathrm{~B}$ & & $1,476 \mathrm{~A}$ & $1,514 \mathrm{~B}$ & \\
\hline Coeficiente de variação (\%) & \multicolumn{2}{|c|}{2,03} & \multicolumn{3}{|c|}{2,33} & \\
\hline
\end{tabular}

Médias seguidas de diferentes letras maiúsculas (linha) e minúsculas (colunas) diferem $(\mathrm{P}<0,05)$ entre si pelo teste $\mathrm{F}$. 
de enzimas pode liberar nutrientes que o animal não necessita ou mesmo não conseguirá converter em maiores índices produtivos. Esse fator pode ter sido determinante nos resultados obtidos. Nesse sentido, é importante a determinação exata do perfil nutricional dos ingredientes para a correta valorização dos nutrientes e obtenção dos resultados esperados.

Não houve efeito $(\mathrm{P}>0,05)$ da adição da xilanase em nenhum dos parâmetros produtivos estudados. O valor médio da energia metabolizável aparente corrigida foi maior em dietas com maior nível de energia metabolizável $(2.900 \mathrm{kcal} / \mathrm{kg})$, entretanto, não houve diferença significativa $(\mathrm{P}>0,05)$ no coeficiente de metabolizabilidade corrigido entre os dois níveis de energia metabolizável (Tabela 4).

No entanto, Kocher et al. (2003) verificaram aumento da energia metabolizável aparente corrigida em dietas à base de milho e farelo de soja para frangos com a dosagem combinada de pectinase, protease e amilase somente quando as dietas basais apresentavam baixa proteína e energia. Da mesma forma, Meng et al. (2005) e Slominski et al. (2006), utilizando a suplementação de enzimas para avaliar o aproveitamento energético das dietas de frangos de corte, verificaram que o uso de enzimas exógenas foram eficientes na degradação dos polissacarídeos não-amiláceos, melhorando o aproveitamento da energia da dieta.

Tabela 3 - Componentes dos ovos de poedeiras alimentadas com rações suplementadas com xilanase

\begin{tabular}{|c|c|c|c|c|c|c|c|c|c|}
\hline \multirow[b]{2}{*}{ Xilanase } & \multicolumn{3}{|c|}{ Gema (\%) } & \multicolumn{3}{|c|}{ Casca $(\%)$} & \multicolumn{3}{|c|}{ Albúmen (\%) } \\
\hline & $\begin{array}{c}2.900 \mathrm{kcal} \\
\mathrm{EM} / \mathrm{kg}\end{array}$ & $\begin{array}{c}2.755 \mathrm{kcal} \\
\mathrm{EM} / \mathrm{kg}\end{array}$ & Média & $\begin{array}{c}2.900 \mathrm{kcal} \\
\mathrm{EM} / \mathrm{kg}\end{array}$ & $\begin{array}{c}2.755 \mathrm{kcal} \\
\mathrm{EM} / \mathrm{kg}\end{array}$ & Média & $\begin{array}{c}2.900 \mathrm{kcal} \\
\mathrm{EM} / \mathrm{kg}\end{array}$ & $\begin{array}{c}2.755 \mathrm{kcal} \\
\mathrm{EM} / \mathrm{kg}\end{array}$ & Média \\
\hline Sem xilanase & 25,04 & 25,02 & 25,03 & 9,25 & 9,27 & 9,26 & 65,71 & 65,71 & 65,71 \\
\hline Com xilanase & 25,40 & 24,85 & 25,12 & 9,19 & 9,30 & 9,25 & 65,41 & 65,85 & 65,63 \\
\hline Média & 25,22 & 24,93 & & 9,22 & 9,29 & & 65,56 & 65,78 & \\
\hline Coeficiente de variação (\%) & & 2,29 & & & 2,40 & & & 0,93 & \\
\hline
\end{tabular}

Tabela 4 - Consumo de ração, com base na matéria seca, coeficiente de metabolizabilidade aparente da matéria seca (CMAMS), energia metabolizável aparente corrigida (EMAn) e coeficiente de metabolizabilidade da energia metabolizável aparente corrigida (CMEMAn) das dietas experimentais

\begin{tabular}{|c|c|c|c|c|c|c|}
\hline \multirow[b]{2}{*}{ Xilanase } & \multicolumn{2}{|c|}{ Energia metabolizável (kcal/kg de ração) } & \multirow[b]{2}{*}{ Média } & \multicolumn{2}{|c|}{ Energia metabolizável (kcal/kg de ração) } & \multirow[b]{2}{*}{ Média } \\
\hline & 2.900 & 2.755 & & 2.900 & 2.755 & \\
\hline & \multicolumn{2}{|c|}{ Consumo de ração (g) } & \multicolumn{4}{|c|}{ CMAMS (\%) } \\
\hline Com xilanase & 2894 & 2931 & 2913 & 73,47 & 74,49 & 73,98 \\
\hline Média & 2866B & 2921A & & 73,81 & 74,36 & \\
\hline \multirow[t]{2}{*}{ Coeficiente de variação (\%) } & \multicolumn{2}{|c|}{2,85} & \multicolumn{4}{|c|}{1,40} \\
\hline & \multicolumn{2}{|c|}{ EMAn (kcal/kg MS) } & \multicolumn{4}{|c|}{ CMEMAn (\%) } \\
\hline Com xilanase & 3.295 & 3.169 & 3232 & 78,17 & 77,90 & 78,04 \\
\hline Média & $3.286 \mathrm{~A}$ & 3.163B & & 77,97 & 77,75 & \\
\hline Coeficiente de variação (\%) & \multicolumn{2}{|c|}{0,97} & \multicolumn{3}{|c|}{0,97} & \\
\hline
\end{tabular}

Médias seguidas de diferentes letras diferem $(\mathrm{P}<0,05)$ entre si pelo teste $\mathrm{F}$.

Tabela 5 - Balanço de nitrogênio das dietas experimentais

\begin{tabular}{|c|c|c|c|}
\hline \multirow[b]{2}{*}{ Xilanase } & \multicolumn{3}{|c|}{$\begin{array}{l}\text { Balanço de nitrogênio } \\
\text { (g N retido/ave/dia) }\end{array}$} \\
\hline & $\begin{array}{c}2.900 \mathrm{kcal} \\
\mathrm{EM} / \mathrm{kg}\end{array}$ & $\begin{array}{c}2.755 \mathrm{kcal} \\
\mathrm{EM} / \mathrm{kg}\end{array}$ & Média \\
\hline Sem xilanase & 1,382 & 1,246 & 1,314 \\
\hline Com xilanase & 1,354 & 1,250 & 1,302 \\
\hline Média & $1,368 \mathrm{~A}$ & $1,248 \mathrm{~B}$ & \\
\hline Coeficiente de variação (\%) & & 6,97 & \\
\hline
\end{tabular}

Médias seguidas de diferentes letras diferem $(\mathrm{P}<0,05)$ entre si pelo teste $\mathrm{F}$.
Mathlouthi et al. (2003), em experimento com frangos de corte, observaram melhor digestibilidade dos nutrientes e da energia metabolizável aparente (EMA) em dietas compostas por milho, farelo de arroz e cevada quando suplementadas com xilanase e $\beta$-glucanase.

As aves alimentadas com dietas do controle positivo e do controle positivo + complexo enzimático apresentaram maior balanço de nitrogênio, entretanto, não houve efeito ( $\mathrm{P}>0,05)$ com a suplementação da xilanase (Tabela 5). 


\section{Conclusões}

A suplementação da enzima xilanase em dietas contendo níveis reduzidos de energia ( $2.755 \mathrm{kcal}$ de $\mathrm{EM} / \mathrm{kg}$ ) melhora a produção e a massa de ovos de poedeiras comerciais de 24 a 48 semanas de idade.

\section{Referências}

BEDFORD, M.R.; CLASSE, H.L.; CAMPBELL, G.L. The effect of pelleting, salt and pentosanase on the viscosity of intestinal contents and the performance of broiler fed rye. Poultry Science, v.70, n.7, p.1571-1577, 1991.

CANTOR, A. Enzimas usadas na Europa, Estados Unidos e Ásia. Possibilidades para uso no Brasil. In: RONDA LATINO AMERICANA DE BIOTECNOLOGIA, 1995, Curitiba. Anais... Curitiba: Alltech, 1995. p.31-32.

CLASSEN, H.L.; CAMPBELL, G.L.; ROSSNAGEL, B.G. Studies on the hull barley in chick diets: deleterious effects and methods of avallution. Canadian Journal of Animal Science, v.65, n.3, p.725-733, 1985.

FUENTE, J.M.; SOTO-SALANOVA, M.F. Utilización de enzimas para mejorar el valor nutritivo de las dietas maízsorgo/soja en avicultura. Seleciones Avicolas. Madrid, p.271-275, 1997.

KOCHER, A.; CHOCT, M. ; ROSS, G. et al. Effects of enzyme combinations on apparent metabolizable energy of corn-soybean meal-based diets in broilers. Journal of Applied Poultry Research, v.12, p.275-283, 2003.

LECZNIESKI, J.L. Enzimas, visão brasileira. In: FORUM DE ENZIMAS, 2006, Curitiba. Anais... Curitiba: DSM Nutritional Products, 2006. p.01-13.

LEESON, S. Programas de alimentación para ponedoras e broilers. In: Curso de Especialización FEDNA, 12., Madrid, 1996. p.201-216.

MATHLOUTHI, N.; MOHAMED, M.A.; LARBIER, M. Effect of enzyme preparation containing xylanase and $\beta$-gucanase on performance of laying hens fed wheat/barley or maize/soybean mealbased diets. British Poultry Science, v.44, p.60-66, 2003.
MENG, X.; SLOMINSKI, B.A.; NYACHOTI, C.M. et al. Degradation of cell wall polysacchardies by combinations of carbohydrase enzymes and their effect on nutrient utilization and broiler chicken performance. Poultry Science, v.84, n.1, p.37-47, 2005.

NY, LE. P.; WYATT, C.; CRESWELL, D. El uso de enzimas para maximizar la utilización de los nutrientes en dietas para ponedoras. In: Enzimas - Desarollando su potencial en dietas para aves basadas en milho/soja. Finfeeds International Inc. Seminário Atlanta, 1998. p.32-37.

PACK, M.; BEDFORD, M. Feed enzymes for corn-soybean broiler diets. A new concept to improve nutritional value and economics. World Poultry Science Journal, v.13, p.87-93, 1997.

ROSTAGNO, H.S.; ALBINO, L.F.T.; DONZELE, J.L. et al. Tabelas brasileiras para aves e suínos: composição de alimentos e exigências nutricionais. Viçosa, MG: Universidade Federal de Viçosa, 2005. 186p.

SILVA, D.J. Análise de alimentos (métodos químicos e biológicos) Viçosa, MG: UFV, 166p. 1990.

SILVA, H.O.; FONSECA, R.A.; FILHO, R.S.G. Características produtivas e digestibilidade da farinha de folhas de mandioca em dietas de frangos de corte com e sem adição de enzimas. Revista Brasileira de Zootecnia, v.29, n.3, p.823-829, 2000.

SLOMINSKI, B.A.; MENG, X.; CAMPBELL, L.D. et al. The use of enzyme technology for improved energy utilization from full-fat oilseeds. Part II: Flaxseed. Poultry Science, v.85, p.1031-1037, 2006.

STRADA, E.S.O.; ABREU, R.D.; OLIVEIRA, G.J.C. et al. Uso de enzimas na alimentação de frangos de corte. Revista Brasileira de Zootecnia, v.34, n.6, p.2369-2375, 2005.

UNIVERSIDADE FEDERAL DE VIÇOSA. SAEG - Sistema de análises estatísticas e genéticas. Versão 8.0. Viçosa, MG: 2000. 59p. (Manual do usuário).

WYATT, C.L.; BEDFORD, M.R. Uso de enzimas nutricionais para maximizar a utilização de nutrientes pelo frango de corte em dietas à base de milho: recentes progressos no desenvolvimento e aplicação prática. In: SEMINÁRIO TÉCNICO FINNFEEDS, 1998, Curitiba. Anais... Curitiba: Finnfeeds, 1998. p.2-12.

ZANELLA, I.; SAKOMURA, N.K.; SILVERSIDES, F.G. et al. Effect of supplementation of broiler diets based on corn and soybeans. Poultry Science, v.78, p.561-568, 1999. 